\title{
A Thought on Applicability of Sun Tzu's Strategy on Marketing Strategy
}

\author{
Fenny Widyani Hartanto \\ Soegijapranata Catholic University \\ fennywidyani@gmail.com \\ Maria Yosephine Dwi Hayu Agustini \\ Soegijapranata Catholic University \\ mariaagustini84@yahoo.com
}

\begin{abstract}
Sun Tzu's strategy is actually an art of war used by Chinese military under Sun Tzu to win the war. Its application has been widespread beyond the military strategy. It has also been adopted for business strategy. This manuscript is to examine applicability of Sun Tzu's strategy on marketing. In particularly it examines if Sun Tzu's strategy can be applied as marketing strategy. Review manuscripts in related topics and a case study on a company are the method for the examination. The result indicates that Sun Tzu's strategy is applicable in marketing and can be related with specific marketing terms.
\end{abstract}

Keywords: marketing strategy, Sun Tzu's strategy, art of war

\section{INTRODUCTION}

Sun Tzu's strategy was originally the ancient Chinese military strategy. It was unknown until 1782 when a French Jesuit priest who lived in China had a copy of the document and translated it into French (Giles, 1910). The translation was considerably uneasy because not everything was written by Sun Tzu. Other translations were conducted since then with improvements. In his translation, Giles (1910) even considered the document as the oldest military treatise in the world and the profoundest among many books on war and fighting.

The Sun Tzu's strategy as we know today was actually a write on the art of war composed by Sun $\mathrm{Wu}$ - the personal name of Sun Tzu which was originally from Wu. His write consists of 13 chapters and was intended to specifically King of Wu named Ho Lu. Later on, Sun Tzu added an exegesis in his book in the form of question and answer between him and King Ho Lu who summoned him about art of war. The Sun Tzu is thus an army strategy for battling enemy in a war. 
The Sun Tzu's Art of War has been applied by many business leaders, executives, and strategists (Jadoul, 2017) and used in variety areas, such as law, military policy, and personal(Starling Social, 2018). This paper addresses application Sun Tzu's strategy for marketing strategy. It is intended to point out an alternative strategy marketers can apply for winning the market.

\section{BASIC CONCEPTS}

\section{The Essence of Marketing Strategy}

Marketing strategy is essential to achieve the company's goals. It is the foundation for company's marketing activities since it can help marketers choose the best way to achieve their goals (Nimble Division, n.d). Marketing strategy is a road map that tells a company where to go and shows the best route to get there. According to Kotler and Keller (2012), marketing strategy relates to organizing marketing functions and marketing activities to achieve company's goals. Its function is to design the selling process of products and services to achieve a sustainable long-term profit for the company.

Marketing strategy needs to be analyzed and evaluated continuously because the dynamic of markets and consumers that keep changing. Kotler and Armstrong (2012) emphasized that marketing is the most dynamic fields in the management area. Such changing creates new challenges for business and the company must respond to those challenges and their responses toward the challenges in the market are reflected in their marketing strategy (Varadarajan, 2010).

Winning the competition in the globalized market is even harder for marketers to do. A marketer needs to know not only their strengths and weaknesses but also their competitors' to win the competition. They thus can calculate their capacity and construct a powerful marketing strategy. Nimble Division (n.d) noted that successful businesses understand the 
winning formula, i.e. an effective marketing strategy. Marketing strategy is a way to organize marketing functions and marketing activities to gain profit (Mongay, 2006) or plans on how to use the company's strengths and capabilities to match the needs and requirements of the market (Ferrell \& Hartline, 2005). It provides concepts and processes which are essential in delivering superior customer value. Logical function of every marketing activity which marketers do to create customer value and achieve profitable customer relationship in business comes from marketing strategy (Kotler \& Armstrong, 2012).

The scope of the marketing strategy is wide and comprehensive. It consists of analysis, strategy development, and implementation of activities in the marketing process (Cravens \& Piercy, 2006). A link between marketing analysis, planning, implementation, and control must be applied in the process of finding a suitable marketing strategy (Kotler \& Armstrong, 2012).

Marketing strategy covers two critical components. First, it is the target market, which describes the selected customers the company wants to address. This component includes segmentation and targeting. The second component is value proposition, which focuses on differentiation and positioning (Chernev \& Kotler, 2014; Kotler \& Armstrong, 2012).

Segmentation is defined as grouping, dividing, separating the market into some consumer groups with the same needs (Goyat, 2011; Hasan, 2009). Since not everyone likes the same product, marketers can start by dividing the market into segments. The purpose of segmentation is to concentrate the marketing energy and forces to particular groups of consumer in order to gain a competitive advantage within the segments.

Marketers identify and profile distinct groups of buyers who might prefer or require different product and service mixes by examining geographic, demographic, psychographic, and behavioral differences among buyers (Kotler \& Keller, 2012). Geographic segmentation is conducted by dividing the market into geographic units such as countries, provinces, 
districts, cities, and many others. Demographic segmentation is to divide the market into groups based on demographic variables such as age, gender, family size, family life cycle, income, jobs, education, religion, and nationality. In psychographic segmentation, consumers are divided into different groups according to social position, lifestyle, and personality traits. Behavior segmentation divides consumers into some groups according to the knowledge level, attitude, use, or response towards some specific products.

Market segmentation strategy is an adaptive strategy. It consists of the operation of the market to select one or more market segments in which the organization could target through the development of specific marketing mixes that are adapted to particular market need (Goyat, 2011). The marketers then choose which segment or segments they want to serve and which one they need to abandon (Hasan, 2009). The targeted segments must be those that are the most profitable and present the most significant opportunities (Kotler \& Keller, 2012).

To create a suitable image for their target market, marketers must choose the positioning of their products in the market (Goyat, 2011; Hasan, 2009; Kotler \& Keller, 2012). Positioning is to place some brands in part of the market where that brand will receive positive feedback better than other competitor products (Hasan, 2009).

Marketing strategy also functions as the guidance for the company to design their integrated marketing mix which is the manifest of the company's marketing strategy. Marketing mix shows the company response toward demand in the specific market. It consists of a set of tactical marketing tools that are blended in order to produce product or service that is suitable for the customers (Kotler \& Armstrong, 2012).

Marketing mix consists of four components called 4Ps: product, price, place, and promotion. The company blends the four components and turn them into real value offered to customers (Kotler \& Armstrong, 2012). Product is a physical object that is sold and has a 
tangible characteristic, a complex set of benefits that could be used to meet customer needs (Pour, Nazari, \& Emami, 2013). Price is the amount of money charged for a product or service. It will determine the level of benefits. Place (or distribution) relates to company's activities that make the product available to the target consumers (Kotler \& Armstrong, 2012; Pour, Nazari, \& Emami, 2013). It includes issues such as distribution channels, market coverage, product inventory, transportation, and distribution sites. Distribution channels are the most critical questions about how an organization could optimize a connection between inner and outer channels (Pour, Nazari, \& Emami, 2013). Promotion refers to company's total marketing communication programs that consists of the specific blend of advertising, personal selling, sales promotion, direct marketing, and public relations tools that the company uses to pursue its marketing objectives.

\section{The Sun Tzu's Strategies}

The art of war wrote by Sun Tzu consists of thirteen chapters (Giles, 1910) and each chapter can be considered as one strategy. Each strategy is outlined briefly below to give basic understanding of each.

\section{Laying Plans}

Laying plans is about planning and calculations in creating art of war that considerably vital according to Sun Tzu. The art of war is governed by five constant factors: the moral law, heaven, earth, the commander, and method and discipline. These five is so important that, as Sun Tzu wrote, he who knows them will be victorious and will not fall. Comparing these factors with those of the opponent to calculate strengths and weaknesses. Many calculations lead to victory and few calculations to defeat. Planning is the most crucial part and there is nothing worth to be pursued without planning (Hor, 2003). 
2. Waging War

It is about a consideration of ways and means. Sun Tzu wrote that in the operations of war there are many chariots and equipment (helmets, bows and arrows, spears and shields, breast-plates, etc.) and hundred thousands of soldier involved. Supplies for foods, armors, and entertainments must be maintained so the soldiers are well equipped and have strengths in battles. These cost a lot. Sun Tzu wrote, a wise general must calculate everything, not only during the battles but also costs for rewarding the soldiers who died and their families. Based on such considerations, the leader of armies can thus decide whether to fight or make peace.

3. Attack by Stratagem

The main goal of attack by stratagem is to win the battle without fighting. Sun Tzu said, "To fight and conquer in all your battles is not supreme excellence; supreme excellence consists in breaking the enemy's resistance without fighting." Moreover, Sun Tzu added the triumph will be complete if losing no man. The leader must be skillful and is able to choose the best strategy (to attack, to surround, or to offer battle) according to the strengths they have compared to the enemy's. How to treat the armies is thus important for them to support the execution of strategy successfully.

4. Tactical Dispositions

Tactical dispositions explain the opportunity to attack the enemies, timing and calculations are essential in this strategy. In the implementation of this strategy, Sun Tzu said: "we must secure ourselves against defeat lies in our own hands, but the enemy himself provides the opportunity of defeating the enemy." This implies that defensive tactics and taking the offensive are the dispositions when insufficient strength occurs. Furthermore, Sun Tzu stressed that "skillful fighter puts himself into a position which makes defeat impossible, and does not miss the moment for defeating the enemy." 
5. Energy

Energy in the art of war is about power, strength, potency, camouflage, and efficiency. According to Sun Tzu, "The control of a large force is the same principle as the control of a few men: it is merely a question of dividing up their numbers. Fighting with a large army under your command is nowise different from fighting with a small one: it is merely a question of instituting signs and signals." By analogy, Sun Tzu described energy is like the bending of a crossbow, while decision is like the releasing of a trigger. A clever combatant will thus look more to the effect of combined energy rather than require more from individuals. In the battle, the able ones usually maintain their camouflage appearance and disguise their strength with weakness in order to deceive their competitors while waiting for the opportunity to attack them.

6. Weak Points and Strong

Stamina, preparations, and calculations are essential in battles. Sun Tzu explained that we must observe our enemies before the battle for being able to defeat them. If we know the enemy's weak points and strategy, we can distract their focus and quickly attack them using our strength to win the battle. A strategic point Sun Tzu put about this is that we will surely succeed in our attacks if we only attack places which are undefended. On the other side, we can save our defense if we can hold our positions that cannot be attacked.

\section{Maneuvering}

This refers to ability of a leader in a battle to take maneuver in terms of moving and changing current conditions into ideal conditions, i.e. to turn indirect into direct and to turn misfortune into gain. The key word here is 'deviation'. It is an advantageous to do maneuver with an army, but it is most dangerous to do it with an undisciplined multitude. Gongs, drums, banners, and flags are considerably more effective to communicate with a 
large army in maneuvering instead of spoken words. Those can be points of attention of the army.

8. Variations in Tactics

Sun Tzu explained that war leaders should prepare many variations in tactics and know the details from all of those tactics before the battles. The main lesson of this strategy is that it is better to be prepared and anticipate any possibilities of being attacked rather than waiting passively for the chances of not being attacked by the enemy.

9. The Army on The March

During the battle, training process, place to rest, and treatments for the troops are essential for some reasons in particularly they contribute to the troops' performances in the battles. The leader must maintain his troops' performance in high level by treating them well during the battles so they can fight well. Mutual gain can be the result.

10. Terrain

Terrain is about the battleground. There are some points here covering accessible, entangling, and temporising. Accessible refers to ground which can be freely traversed by both sides; entangling refers to ground which can be abandoned but is hard to occupy; and temporizing is ground which neither side will gain by making the first move. In a battle, the leader should analyze their battleground first then make calculations and preparations to cope, take over, or hold the ground. Here, Sun Tzu also taught how to treat the soldiers. The leader should regard their soldiers as their children and they will be very loyal even until death. Sun Tzu also stated "if you know the enemy and know yourself; your victory will not stand in doubt; if you know Heaven and know Earth, you may make your victory complete." 


\section{The Nine Situations}

This refers to nine varieties of ground: (1) dispersive ground, (2) facile ground, (3) contentious ground, (4) open ground, (5) ground of intersecting highways, (6) serious ground, (7) difficult ground, (8) hemmed-in-ground, and (9) desperate ground. Each variety leads to a specific strategy. For example, we should not fright on dispersive ground but should fight on desperate ground. We should not try to block the enemy's on open ground, and so on. It is also important to pay attention on well-being of the soldiers and set up one standard of courage on the army for succeeding the actions. However, different measures should be set that suit to the nine grounds accordingly.

\section{The Attack by Fire}

Fire is a weapon for attacking enemy. According to Sun Tzu, there are five ways of attacking with fire: (1) burn soldiers in their camp, (2) burn stores, (3) burn baggage trains, (4) burn arsenals and magazines, and (5) hurl dropping fire amongst the enemy. To do this effectively, means and materials must be available, and conditions (such as weather and movements of stars) must be calculated. Use of intelligence must obviously occur in using fire as a mean of attack.

\section{The Use of Spies (Intelligence)}

In war, spies held important and dangerous positions for gathering and develop trusted information sources about the enemy. There are five classes of spies: (1) local spies, (2) inward spies, (3) converted spies, (4) doomed spies, and (5) surviving spies. A leader needs information about the enemy ('foreknowledge') to make accurate calculations about the enemy's reactions and to make reference on making decisions. Sun Tzu closed this chapter by stating 'spies are the most important element in water, because on them depends an army's ability to move." 


\section{REVIEW ON APLICABILTY}

\section{The Sun Tzu's Strategy in Marketing}

Principles of military combat can be translated into business combat (Essays, 2018). Sun Tzu's enemy may be regarded as a metaphor. Jadoul (2017) noted that enemy in this context can be regarded as a business opportunity to pursue, and the war as the process of conquering consumers' heart, mind, and wallet. Many have adapt the art of war into business situation. McNeilly (1996) extracted the thirteen strategies of Sun Tzu into six principles that are suitable and applicable for business.

1. Win All Without Fighting. The main focus of this principle is to capture the market without destroying it. Marketers must not only use their knowledge about market conditions and customers' preferences but also learn about the company's and competitors' strength points.

2. Avoid Strength, Attack Weakness. Here, Sun Tzu taught to strike the enemy to the point where they least expect it.

3. Deception and Foreknowledge. The point of this is to maximize the power of market information.

4. Speed and Preparation. This principle teaches us to move swiftly to overcome competitor.

5. Shape Your Opponent. In this principle, we must employ a strategy to master the competition.

6. Character-Based Leadership. Leadership is important and character-based leadership can provide effective leadership style in turbulent times.

Michaelson and Michaelson (2004) translated the Sun Tzu's strategy into twelve principles that are applicable for marketing.

1. Honor the Customer. Different target markets have different preferences for products and services. Marketers must thus be selective in choosing suitable target markets so they can 
give significant effects on how to treat their customers and to build a lifelong relationship with the customers. The marketing strategy must focus on reaching the primary target market and make consumers satisfy with the products or services offered by the company.

2. Organization of Intelligence. Preparation before entering the market is essential. Marketers must do some research to explore characteristics of their markets, to gain important information, and to conduct competitive analysis. Here, the company must also protect their secrets from the competitors because, according to Sun Tzu, "there is no place where espionage is not possible."

3. Maintenance of the Objective. A leader must have a clear and specific intention on the battlefield. The leader must develop an action plan, apply it, take the risks which already calculated before, and never underestimate their competitors. Maintain objectives and find out a winning strategy are the requirements. This is in accordance to Sun Tzu's principle of to win without fighting.

4. A Secure Position. The company must reach a position that is uneasily replaced by its competitors.

5. Offensive Action. It provides company initiatives in movement and keeps the company in control.

6. Surprise. It relates to ways that surprise or disrupt the competitors' focus. The company must create skillful planning that can generate a mismatch in competitors and keep them confused with the company's real intention. A way is categorized as a surprise when it is too late for the competitor to react.

7. Maneuver. In marketing, maneuver is about the way of thinking to turn the position from disadvantage into advantage. In the process of maneuver, the company must also think about how to leverage opportunities and choose suitable strategy on the battlefield. 
8. Concentration of Resources. This principle is considerably the key to success in marketing attack. In this principle, marketers must identify the customers' needs, observe market conditions, and find a profitable market for their products or services. The company can then concentrate its resources to the identified profitable market.

9. Economy of Force. The main focus of this principle is to effectively use the resources of the company, build internal strength, and choose the battle. Return on investment also becomes an indicator that is needed in the economy of force. Usually, a company uses all of its resources for their main effort.

10. Command Structure. The command structure is essential and correlates with human resources department. It links the principles so they can be applied effectively. Morale plays significant role in this principle. It is the result of what a leader build in the company and part of a proper management. A leader has an essential role by giving examples of 'right things' that the followers will do the same. Communication between leaders and followers must also be clear.

11. Personal Leadership. This principle addresses the leader's leadership capability. A leader must listen and learn to be more critical. They should improve their leadership ability continuously and keep a positive attitude in order to provide vision and build morale in the company. Faith and trust between the leader and followers are thus essential for the leaders gain loyalty from their followers. Furthermore, the leader also need to combine their leadership strength with their management strength, know the arts of leadership, and beware of their blind spots.

12. Simplicity. Simplicity is essential for executing the plans. Since practically the most straightforward plans are challenging to execute, a leader should break down the most significant plan into the smallest ones and gives the most straightforward task to the 
followers to accomplish them. A leaderalso needs to communicate their instructions to the followers in the simplest way.

McNeilly (1996) and Michaelson and Michaelson (2004) are among many of those who adopt Sun Tzu's strategy for business. Their principles are relatively comprehensive compared to others who only take some principles according to the specific purposes. For example, Jadoul (2017) adopted the Sun Tzu's strategy in particularly sales strategy. Based on chapter 10 of Sun Tzu's strategy, Terrain, he said that marketers must know their customers, the environment in which they work or live, and opportunities and challenges before addressing them. It means preparation is the key. As chapter 6, marketers must know their weak points \& strong and make plans carefully and accordingly by build a message house, define the pitch, craft presentation, and plan meeting carefully (chapter 8: variation in tactics). In executing the plan, Jadoul (2017) also emphasized the importance to support for example the presentation with proper visuals and multimedia testimonials such as banners, flags, gongs, drums (chapter 7: maneuvering). Finally, he stressed about being focus (chapter 5: energy). Here, marketers must be direct, consistent, and clear toward they are doing.

Starling Social (2018) provides '6 killer' marketing lessons from Sun Tzu by adopting quotes made by Sun Tzu rather than chapters of the strategy. In essence, they said that we must be creative with our marketing approach and try new things to find solutions creatively by blending primary colors (blue, yellow, red, white, and black) to create a rainbow in order to overcome the limitations in budget, knowledge, or time (lesson1). If we are fail or the plans do not go as we intended, they suggest us not to be afraid to retreat and regroup our plans (lesson 2). To be effective, marketing needs discipline and execution. Discipline refers to strategic aspect such as maintaining a macro-level and long-term vision which incorporates a well-developed marketing strategy. Execution relates to tactical aspects which involve for example day-to-day marketing tasks, review goals and KPIs regularly to maintain paths 
toward goals. These are lesson 3. In lesson 4, they emphasized importance to pay attention to market trends, competition, and other influencers in the industry. However, being flexible and seizing on opportunities are better than the plan itself (lesson 5). Finally in lesson 6 they reminded that 'successful marketers are ones who are agile.' This means that marketers must take actions based on data, facts, and what is and isn't working and not repeating the actions.

Other examples of those adopting Sun Tzu's strategy for marketing are numerous. Each interprets either the strategies (or chapters) or quotes for specific purposes in marketing (see for example (123456, 2013; Essays, 2018; Miller, 2016). These show that Sun Tzu's Art of War is widely applicable and many examine that it is the most prudent and thoughtful analysis of strategy relevant not only in that time but also in current time. In other words, its applicability is obvious in many areas.

\section{Implementation the Sun Tzu's Strategy on a Company}

We conducted an examination of the application of Sun Tzu's strategy on marketing strategy of a company. The company is an engineering company providing services on particularly reparations, maintenance, and custom modifications of manufacturing machine. It serves manufacturing companies and other engineering companies (B2B market). The market is very dynamic with fast advancement of technology and highly competitive but also is very potential. The company chooses to serve a niche market consisting foreign and local companies having concern on quality and reliability of products and services.

For practical reason, the examination is based on the twelve principles developed by Michaelson and Michaelson (2004) rather than on the original version of Sun Tzu's. The result presented in the table 1 indicates that the company's marketing strategy is compatible with the principles.

Table 1. Implementation the Twelve Principles in the Company's Marketing Strategy 


\section{No The Sun Tzu Principle}

1 Honor the Customer

(Know the customers: who they are, what they want, and what to give to them)

\section{Organization of Intelligence} (Know your market as well as know yourself)

\section{Implementation}

The company chooses to serve foreign and local companies that praise high quality. It continuously identifies, analyzes, and matches their offers to customers' needs by improving the quality of products and services to satisfy the customers through the program of 5Rs.

The company collects, analyzes and evaluates data about prospective customers, existing customers, and competitors. This becomes the task of Marketing and Development Department to understand whether the customers' business is healthy or not.

3 Maintenance of the Objective The company always maintains its objective to (A clear intention and a steady aim) provide the best quality of products and services for their customers and strict to its mission to provide them in timely manner. The vision to be the trusted and reliable engineering company lead the company to always put top priority on quality and service in order to create good image and reputation among their customers and leaves a good and deep impression in their customers' minds. 
No The Sun Tzu Principle

4 A Secure Position

(Occupy a position that cannot speed, accuracy, and quality to their customers quickly be taken by your opponents)

who do not put price as an issue. The company knows that their products and services are crucial to the customers' process of production that can possibly create production shutdown.

The company sometimes works together with competitors having the same standard through sub-contracts when the time is very tight.

5 Offensive Action The company puts priorities in giving the best (Keep on the offensive to secure freedom of action)

it. They keep the technicians to be skillful and are easy to be contacted at any time. They do not want to fight in the cheap and low-quality product that may create complaints and costly maintenance but serve only customers who prefer their good quality of product and service that do not need significant maintenance costs.

6 Surprise A way the company conducts to surprise the (Surprise is the best way to gain competitors is by creating breakthrough in the psychological dominance and deny new products and developing better technologies the initiative to your opponent) for the competitors to unease to follow. 
No The Sun Tzu Principle

$7 \quad$ Maneuver

(The most natural routes are often the most heavily defended; the most extended way round can be the shortest way home) for clients even though there is no a signed contract yet. They keep the detail calculation and will forward it to the client after the contract is signed.

8 Concentration of Resources (Mass sufficiently superior force at the decisive place and time)

9 Economy of Force The company thinks that the most important (Assess where you employ your resources accurately) build morale, loyalty, and discipline of their employees through appropriate reward and punishment to particularly salespersons for enabling them to leverage sales that contribute to ROI.

10 Command Structure The company makes sure that every employee (The management process unleashes knows their job description and what they are 


\section{No The Sun Tzu Principle Implementation}

the power of human resources) doing. The human resource department has responsible for this.

The company treats the employees as the family

(It requires the leader's faith in his or members, builds good relationship with them, her people and their faith in the and cares about their family welfare. It does not leader's ability to win) only provides reward and punishment in their job but also helps their family by giving for example scholarship for their children.

12 Simplicity The company applies job specialization for every (Even the most straightforward plans employee has special skills and they are trained are difficult to execute) according to the marketing needs.

\section{CONCLUSION: FINAL THOUGHTS}

In the disruptive era, which everything is easily accessed and connected through the internet, sound marketing strategy becomes more important for companies to achieve their goals. Marketers need to evaluate their marketing strategy continuously to keep up with the dynamic in the market. Otherwise, they may fail and are left behind.

The Sun Tzu's strategy is surely applicable in marketing. Its principles can flexibly fit in marketing issues. The essence of marketing is to battle and win consumers' heart and a company should always strive and maintain its market from competitors who may keep attacking it. One quote of Sun Tzu reminds marketers about this: "If you know the enemy and know yourself, you need not fear the result of a hundred battles. If you know yourself but not the enemy, for every victory gained you will also suffer a defeat. If you know neither the enemy nor yourself, you will succumb in every battle"(Giles, 1910, p. 8). 
However Sun Tzu reminded way of effective attack. It can be said that marketers must pay attention to the strategy in capturing their market without destroying it in the process. Destroying the market will make it unprofitable for the business. In other words, the best method for marketers to win the competition is to choose the marketing strategy without drawing the competitor's attention. For this, Sun Tzu said, "Hence to fight and conquer in all your battles is not supreme excellence; supreme excellence consists of breaking the enemy's resistance without fighting" (Giles, 1910, p. 7). Sun Tzu's strategy will probably have been relevant for decades and be guidance for marketers to be prudent and thoughtful in developing marketing strategy.

\section{REFERENCES}

123456, 1. (2013, July 2). 10 Executive Marketing Lessons from Sun Tzu's the Art of War. Retrieved from Relevance, Content Promotion News \& Insights: https://www.relevance.com/blog/10-executive-marketing-lessons-from-sun-tzus-theart-of-war/

Chernev, A., \& Kotler, P. (2014). Strategic Marketing Management, 8th Edition. Cerebellum Press.

Cravens, D., \& Piercy, N. (2006). Strategic Marketing, 8th Edition. McGraw-Hill.

Essays, U. (2018, November). The Sun Tzu Marketing Strategies. Retrieved from UK Essays: https://www.ukessays.com/essays/marketing/the-sun-tzu-marketing-strategiesmarketing-essay.php?vref=1

Ferrell, O., \& Hartline, M. (2005). Marketing Strategy, Third Edition. South-Western: Thomson Corporation.

Giles, L. (1910). The Art of War Sun Tzu, The Oldest Military Treatise in the World. British: The Puppet Press.

Goyat, S. (2011). The Basis of Market Segmentation: A Critical Review of Literature. European Journal of Business and Management, 3(9), http://www.iiste.org.

Hasan, A. (2009). Marketing. Media Pressindo.

Hor, K. (2003). Applying Sun Tzu's Art of War in Marketing. Bhuana Ilmu Populer. 
Jadoul, M. (2017, February 15). Marketing Lessons from Sun Tzu. Retrieved from B2B Story Telling: https://b2bstorytelling.wordpress.com/2017/02/15/marketing-lessons-fromsun-tzu

Kotler, P., \& Armstrong, G. (2012). Principles of Marketing, 14th Edition. Boston: Pearson Prentice Hall.

Kotler, P., \& Keller, K. (2012). Marketing Management, 14th Edition. Pearson Education.

McNeilly, M. (1996). Sun Tzu and the Art of Business: Six Strategic Principles for Managers. Oxford: Oxford University Press.

Michaelson, G., \& Michaelson, S. (2004). Sun Tzu Strategies for Marketing: 12 Essential Principles for Winning the War for Customers. McGraw-Hill.

Miller, C. (2016, January 6). 3 Essential Marketing Lessons from Sun Tzu's the Art of War . Retrieved from SocialMediaToday: https://www.relevance.com/blog/10-executivemarketing-lessons-from-sun-tzus-the-art-of-war/

Mongay, J. (2006). Strategic Marketing. A Literature Review on Definitions, Concepts and Boundaries. MRPA Paper No. 41840). n.d: Munich Personal RePEc Archive. Retrieved from https://mpra.ub.uni-muenchen.de/41840

Nimble Division. (n.d). The Importance of Marketing Strategy. New York: Nimble Division .

Pour, B., Nazari, K., \& Emami, M. (2013). The Effect of Marketing Mix in Attracting Customers: Case study of Saderat Bank in Kermanshah Province. African Journal of Business Management, https://doi.org/10.5897/AJBM12.127.

Starling Social. (2018, June 11). 6 "Killer" Marketing essons from Sun Tzu's Art of War. Retrieved from Starling Social: https://starling.social/blog/post/40/6-killer-marketinglessons-sun-tzus-art-war

Varadarajan, R. (2010). Strategic marketing and marketing strategy: Domain, definition, fundamental issues and foundational premises. Journal of the Academy of Marketing Science, https://doi.org/10.1007/s11747-009-0176-7. 